\title{
Interleukin-6 Enhances Hypercalcemia and Bone Resorption Mediated by Parathyroid Hormone-related Protein In Vivo
}

\author{
Jose De La Mata, * Harry L. Uy, * Theresa A. Guise, * Beryl Story, ${ }^{\star}$ Brendan F. Boyce, ${ }^{\star}$ Gregory R. Mundy, * \\ and G. David Roodman $\$ \$$ \\ *Department of Medicine and ${ }^{\ddagger}$ Department of Pathology, University of Texas Health Science Center, San Antonio, Texas 78284; \\ and ${ }^{8}$ the Audie Murphy Veterans Administration Hospital, San Antonio, Texas 78284
}

\section{Abstract}

Tumors frequently induce the multifunctional cytokine $\mathbf{L}-6$, which has been linked to several paraneoplastic syndromes, most notably cachexia. IL-6 stimulates osteoclast formation, causes mild hypercalcemia, and is produced by bone cells in vitro upon exposure to systemic hormones. Since IL-6 is produced together with parathyroid hormone-related protein (PTH-rP) in some patients with cancer, we tested the hypothesis that production of IL-6 potentiates the effects of PTH-rP on $\mathrm{Ca}^{2+}$ homeostasis and osteoclastic bone resorption and examined potential mechanisms for these interactions in vivo. Chinese hamster ovarian (CHO) cells stably transfected with cDNAs for IL-6 (CHO/IL-6) and PTHrP sense (CHO/PTH-rP) or antisense (CHO/PTH-rP AS) were inoculated intramuscularly into nude mice. Experimental groups included CHO/IL-6 plus CHO/PTH-rP; CHO/IL-6 plus CHO/PTH-rP AS; CHO/IL-6 alone; and CHO/PTH-rP alone. Blood ionized $\mathrm{Ca}^{2+}$ was measured on days $0,7,10,12$, and 13. Three different developmental stages in the osteoclast lineage were examined at day 13: the early multipotential precursor, granulocyte macrophage colony-forming units (CFU-GM); more mature mononuclear osteoclast precursors, assessed by their capacity to form tartrate-resistant acid phosphatase-positive multinucleated cells in marrow cultures; and mature osteoclasts, assessed by histomorphometry. IL-6 increased CFU-GM but not bone resorption or $\mathrm{Ca}^{2+}$. In contrast, PTH-rP induced hypercalcemia and bone resorption and increased multinucleated osteoclasts and more mature precursors cells, but not CFU-GM. However, mice treated with both IL-6 and PTH-rP had very marked hypercalcemia and osteoclastosis as well as an increase in the number of both CFU-GM and mature osteoclast precursors. These data demonstrate that IL-6 enhances PTH-rP-mediated hypercalcemia and bone resorption, most likely by increasing the pool of early osteoclast precursors that in turn can differentiate to mature osteoclasts. We conclude that IL-6 stimulatory effects on osteoclast precursors may enhance the effects of other bone resorption factors that act at later stages in the osteoclast lineage. (J. Clin. Invest. 1995. 95:2846-2852.) Key words: osteoclast • malignancy $\bullet$ cytokine $\bullet$ parathyroid hormonerelated protein • interleukin- 6

Address correspondence to Dr. G. David Roodman, Research Services (151), Audie Murphy VA Hospital, 7400 Merton Minter Boulevard, San Antonio, TX 78284. Phone: 210-617-5319; FAX: 210-567-4705.

Received for publication 1 November 1994 and in revised form 30 December 1994.

The Journal of Clinical Investigation, Inc.

Volume 95, June 1995, 2846-2852

\section{Introduction}

The syndromes of hypercalcemia and cachexia frequently occur together in patients with cancer. In both situations, the clinical syndromes are mediated by a factor(s) produced by the tumors or by the host in response to the tumor, since they are abrogated after successful tumor excision. Parathyroid hormone-related protein (PTH-rP) ${ }^{1}$ is implicated in the hypercalcemia of malignancy $(1,2)$, particularly in the case of solid tumors, and IL-6 is implicated in cachexia. However, like PTH-rP, IL-6 has also been implicated in the syndrome of humoral hypercalcemia (3) and can stimulate osteoclastic bone resorption (4). Although it is not known how frequently these factors are produced together in patients with cancer, we reasoned that in those patients in whom they are produced together the combined effects may be synergistic. To test this hypothesis, we used Chinese hamster ovarian ( $\mathrm{CHO}$ ) cells stably transfected with human PTH-rP cDNAs in the sense and antisense orientations as well as similar cells transfected with the cDNA for murine IL-6. We then inoculated these tumors alone and together into nude mice and examined their combined effects on $\mathrm{Ca}^{2+}$ homeostasis, bone resorption, capacity to stimulate osteoclast formation, and cachexia.

\section{Methods}

Cells

Nontransfected $\mathrm{CHO}$ cells $(\mathrm{CHO} /-)$ and $\mathrm{CHO}$ cells stably transfected with cDNA for either murine IL-6 (CHO/IL-6) (5) or human PTH-rP(1-141) in the sense (CHO/PTH-rP) and antisense (CHO/PTH-rP AS) (6) orientations were cultured in DME (Gibco Laboratories, Grand Island, NY) with $10 \%$ FCS (Hyclone, Logan, UT) and $0.1 \%$ penicillin/ streptomycin (Sigma Chemical Co., St. Louis, MO) at $37^{\circ} \mathrm{C}$ in a humid atmosphere of $5 \% \mathrm{CO}_{2} /$ air. The $\mathrm{IL}-6$-producing $\mathrm{CHO}$ cells were a generous gift from Dr. Rennick (DNAX, Palo Alto, CA).

\section{Animals}

Male BALB/c nude mice (from the breeding colony at the Audie Murphy V.A. Hospital, San Antonio, TX), 4-6 wk of age, were housed in a laminar flow isolator hood with a 12-h-light/12-h-dark cycle. Water was acidified, to $\mathrm{pH} 3$, and supplemented with $0.5 \mathrm{~cm}^{3}$ of multivitamins (Lymphomed Inc., Melrose Park, IL) for every 2 liters. Autoclaved mouse chow (Ralston-Purina, St. Louis, MO) was provided ad libitum. Four independent experiments were performed with four experimental groups of mice in each (four mice per group). In all four experiments, mice were inoculated intramuscularly into each thigh with $10^{7} \mathrm{CHO}$ cells suspended in $0.1 \mathrm{ml}$ of PBS. Experimental groups in the initial experiment included mice inoculated with $\mathrm{CHO} / \mathrm{IL}-6$ cells in the right

1. Abbreviations used in this paper: CFU-GM, granulocyte macrophage colony-forming unit; $\mathrm{CHO}$, Chinese hamster ovarian; PTH-rP, parathyroid hormone-related protein; TRAP $(+) \mathrm{MNC}$, tartrate-resistant acid phosphatase-positive multinucleated cell. 
thigh and CHO/PTH-rP cells in the left thigh (designated as IL-6/ PTH-rP); mice inoculated with CHO/PTH-rP cells in the right thigh (designated as PTH-rP); and mice inoculated with $\mathrm{CHO} / \mathrm{IL}-6$ cells in the right thigh (designated as IL-6). Finally, as a control for IL-6/PTH$\mathrm{rP}$ mice, animals were inoculated with $\mathrm{CHO} / \mathrm{IL}-6$ cells in the right thigh and CHO/PTH-rP AS cells in the left thigh (designated as IL-6/PTHrP AS). In three subsequent experiments, all mice were inoculated with two tumors as follows: IL-6/PTH-rP mice were inoculated with $\mathrm{CHO}$ / IL-6 cells in the right thigh and CHO/PTH-rP cells in the left thigh. IL-6 mice were inoculated with CHO/IL-6 cells in the right thigh and nontransfected CHO cells in the left thigh. PTH-rP mice were inoculated with $\mathrm{CHO} / \mathrm{PTH}-\mathrm{rP}$ cells in the right thigh and nontransfected $\mathrm{CHO}$ cells in the left thigh. Control mice were inoculated with nontransfected CHO cells in both thighs. Blood was collected by retroorbital phlebotomy under metofane anesthesia. Whole blood ionized $\mathrm{Ca}^{2+}$ was measured before tumor inoculation (day 0 ), on days 7,10 , and 12 , and at time of killing (day 13) using a $\mathrm{Ca}^{2+}-\mathrm{pH}$ analyzer (model 634; Ciba Corning, Medfield, MA). $200 \mu \mathrm{l}$ of plasma was collected in $400 \mathrm{KIU} / \mathrm{ml}$ aprotinin (Sigma Chemical Co.) and EDTA before tumor inoculation and at time of killing and stored at $-70^{\circ} \mathrm{C}$ until assayed for PTH-rP, IL-6, IL-1, and TNF $\alpha$. Mice were weighed on days 0 and 7 and at time of killing. Tumor diameters (long axis $[L]$ and mean mid-axis width $[W]$ ) were measured using calipers on day 7 and at time of killing, and tumor volume was estimated from these measurements using the formula for the volume of an ovoid: tumor volume $=4 / 3 \pi \times L / 2(W / 2)^{2}$. Anesthetized mice were killed $13 \mathrm{~d}$ after tumor inoculation by cervical dislocation, and a pool of femoral bone marrow cells was made from each group. Bone marrow cells were then processed for colony assays and marrow culture as described in the following section. Calvariae were dissected for bone histology and histomorphometry, as will be described.

\section{Assays}

Granulocyte macrophage colony-forming unit assay. To determine the effect of IL-6, PTH-rP, and the combination of both on early stages of cells in the osteoclast lineage, we examined the number of granulocyte macrophage colony-forming units (CFU-GM), which contain the earliest identifiable osteoclast precursors (7). For this purpose, femurs were removed aseptically and dissected free of adherent tissue. Bone ends were cut, and the bone marrow was flushed with $\alpha$-MEM with $0.1 \%$ penicillin/streptomycin using a 25 -gauge needle. Bone marrow cells ( 5 $\times 10^{6} / \mathrm{ml}$ ) were suspended in $\alpha$-MEM with $15 \%$ charcoal-treated FCS (Hyclone), and incubated for $2 \mathrm{~h}$ at $37^{\circ} \mathrm{C}$ in an atmosphere of $5 \% \mathrm{CO}_{2} /$ air to allow cells to attach to the plastic. The nonadherent bone marrow cells $\left(10^{5} / \mathrm{ml}\right)$ were removed and plated on $35-\mathrm{mm}$ tissue culture dishes (Falcon Plastics, Lincoln Park, NJ) in a 1-ml volume of $0.8 \%$ methylcellulose (Aldrich Chemical Co., Milwaukee, WI) supplemented with $20 \%$ charcoal-treated FCS, BSA (Sigma Chemical Co.), and $1.25 \mathrm{ng} / \mathrm{ml}$ recombinant murine GM-CSF (Intergen Co., Purchase, NY) as the source of colony-stimulating activity. Each assay was performed in triplicate. Cultures were incubated at $37^{\circ} \mathrm{C}$ in an atmosphere of $5 \% \mathrm{CO}_{2} /$ air for $7 \mathrm{~d}$, at which time colonies ( $>40$ cells) and clusters ( $>10$ and $<40$ cells) were counted.

Bone marrow cultures. To determine the effect of IL-6, PTH-rP, and the combination of both on more committed marrow osteoclast precursors, we cultured nonadherent mononuclear cells from the bone marrow on plastic and dentine slices and counted the number of tartrateresistant acid phosphatase-positive multinucleated cells (TRAP(+) MNCs) formed. For this purpose, nonadherent bone marrow cells were cultured in $\alpha$-MEM containing $15 \%$ heat-inactivated FCS (Hyclone) at $2 \times 10^{6}$ cells per $\mathrm{ml}$ in 24-well plates (Falcon Plastics). 1,25-Dihydroxyvitamin $D_{3}\left(10^{-8} M\right)$, a generous gift of Dr. Uskokovic (HoffmanLa Roche, Nutley, NJ), was added to each well and every $2 \mathrm{~d}$ thereafter. After $6 \mathrm{~d}$, the cells were fixed and stained for TRAP using a commercially available kit (Sigma Chemical Co.). TRAP $(+)$ MNCs with three or more nuclei per cell were counted by light microscopy.

Bone histology and histomorphometry. To determine the effects of IL-6, PTH-rP, and the combination of both on mature osteoclasts, we removed calvariae from these mice and performed quantitative histomorphometric analysis. Calvarial bones were fixed in $10 \%$ buffered

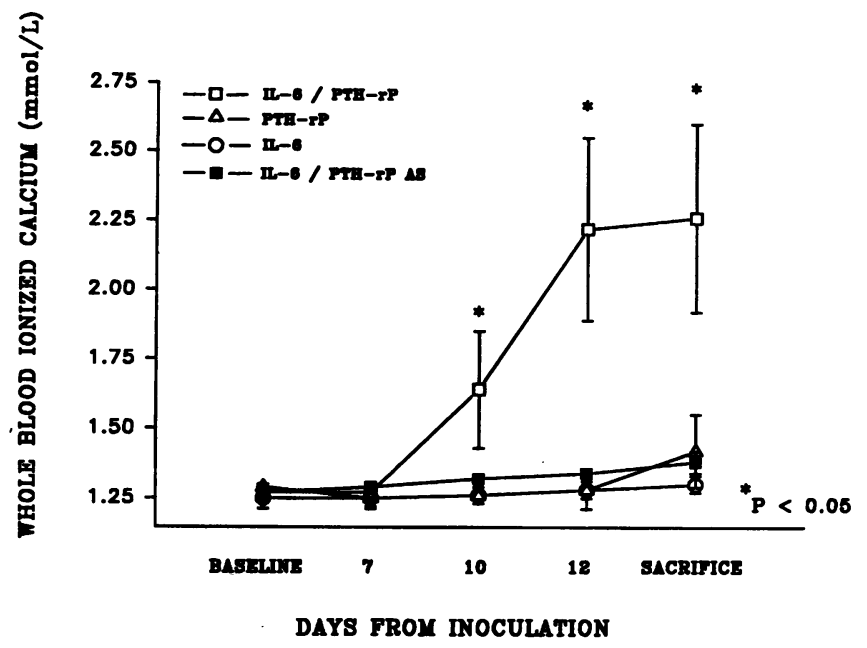

Figure 1. Effects of $\mathrm{CHO}$ tumors on blood ionized $\mathrm{Ca}^{2+}$. Nude mice were inoculated with $\mathrm{CHO} / \mathrm{IL}-6, \mathrm{CHO} / \mathrm{PTH}-\mathrm{rP}$, and $\mathrm{CHO} / \mathrm{IL}-6$ tumors together with CHO/PTH-rP or CHO/PTH-rP AS tumors at day 0. For each group, $n=4$. Values represent mean \pm SD. Similar effects were observed in three independent experiments.

formalin, decalcified in 14\% EDTA, and embedded in paraffin after processing. 3- $\mu \mathrm{m}$ sections were cut anterior to and parallel with the lambdoid suture and stained with hematoxylin and eosin. Using a computerized Bioquant image analysis system (R \& M Biometrics, Nashville, TN), we measured the following variables: total bone area (i.e., the area of bone between the sagittal suture and the lateral border); total eroded and osteoclast surfaces (i.e., the extent of crenated surfaces and of crenated surfaces associated with osteoclasts, respectively, expressed as a percentage of the total length of the interface between bone and bone marrow inside the calvaria); and osteoclast numbers (expressed per square millimeter of the total bone area).

$P T H-r P$ radioimmunoassay. Plasma PTH-rP concentrations were determined using a PTH-rP immunoradiometric assay (Nichols Institute Diagnostics, San Juan Capistrano, CA) that detects PTH-rP-(1-72) (8). The calculated sensitivity of this assay was $0.3 \mathrm{pmol} / \mathrm{liter}$.

$I L-6, I L-1$, and TNF $\alpha$ assays. Murine $I L-6$ plasma concentrations were determined by a commercially available ELISA kit (Endogen, Boston, MA) that detected a minimum of $15 \mathrm{pg} / \mathrm{ml}$ immunologically active murine IL-6. Plasma concentrations of murine IL-1 $\alpha$ and TNF $\alpha$ were determined with commercial immunoassay kits (Genzyme Corp., Cambridge, MA).

\section{Statistical analysis}

Results are expressed as mean $\pm S D$. Differences in the hypercalcemic response to IL-6, PTH-rP, or the combination of both were determined using ANOVA followed by Tukey's post test. Student's $t$ test for unpaired samples was used for testing differences in the plasma factor concentrations, tumor volume, CFU-GM (colony) assays, and marrow multinucleated cell formation. Differences in histomorphometric variables in the calvarial sections were determined using ANOVA. $P$ $<0.05$ were considered significant.

\section{Results}

Effects of tumors on blood ionized $\mathrm{Ca}^{2+}$. A significant hypercalcemic response occurred $10 \mathrm{~d}$ after tumor inoculation in IL-6/ PTH-rP mice. In contrast, at this time IL-6, PTH-rP, and IL-6/ PTH-rP AS tumor-bearing animals remained normocalcemic (Fig. 1). At the time of killing, a very marked difference in the magnitude of the hypercalcemic response was observed between IL-6/PTH-rP and IL-6/PTH-rP AS mice. IL-6/PTH-rP AS 

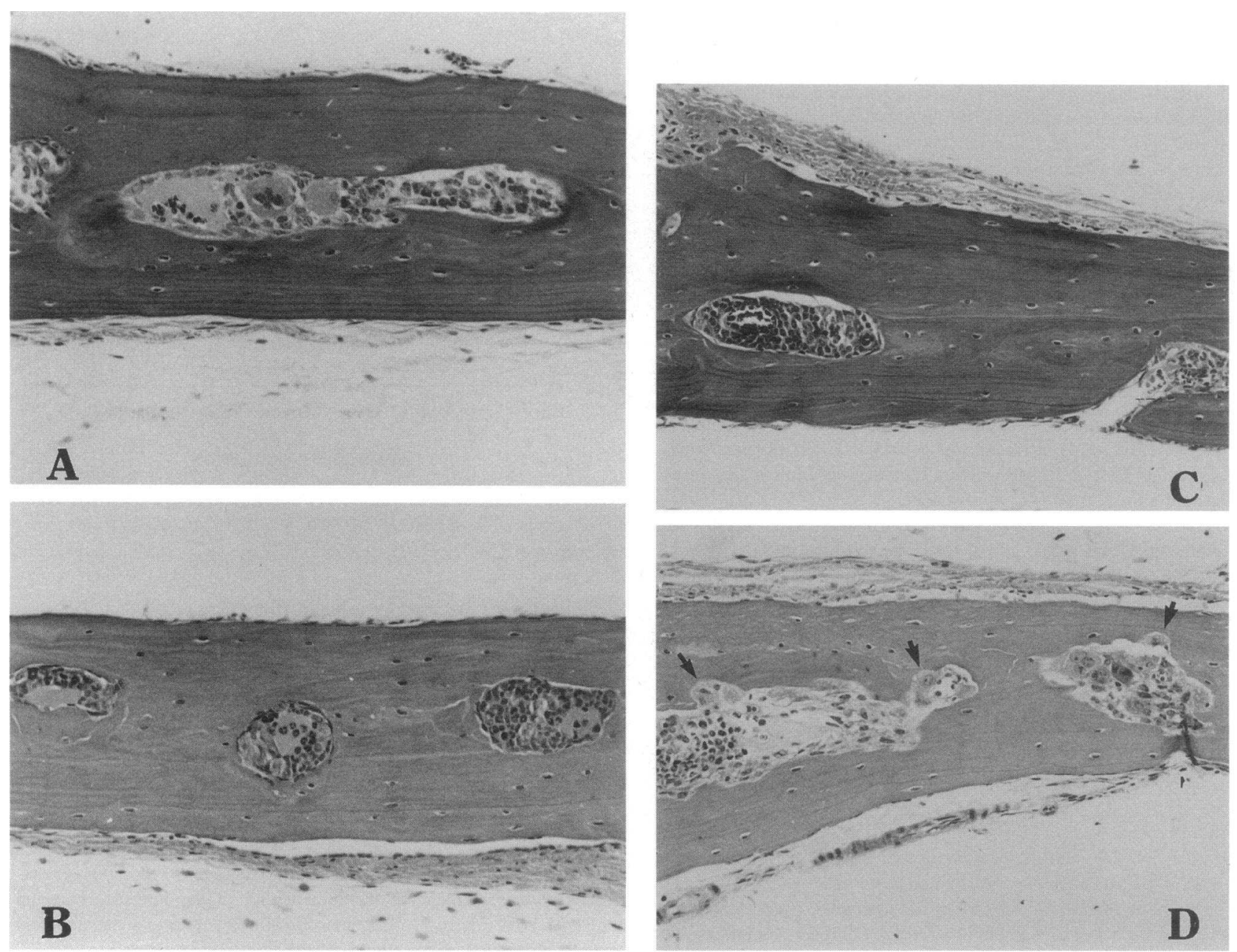

Figure 2. Decalcified calvarial sections of nude mice bearing CHO/IL-6 tumors $(C)$, CHO/PTH-rP tumors $(B)$, and CHO/IL-6 tumors together with CHO/PTH-rP $(D)$ or CHO/PTH-rP AS $(A)$ killed $13 \mathrm{~d}$ after tumor inoculation. Osteoclasts (present only in the IL-6/PTH-rP group) are indicated by arrows. Magnification, 20. For each group, $n=4$. Values represent mean \pm SD. Similar effects were observed in two independent experiments.

mice had a very mild increase in their $\mathrm{Ca}^{2+}$ concentrations $(1.37 \pm 0.04 \mathrm{mmol} / \mathrm{liter}$, mean $\pm \mathrm{SD})$ similar to that found in IL-6 animals $(1.3 \pm 0.18 \mathrm{mmol} /$ liter $)$. Although at time of killing PTH-rP mice exhibited moderate hypercalcemia (1.42 \pm 0.14 $\mathrm{mmol} /$ liter $), \mathrm{Ca}^{2+}$ concentrations were significantly lower than those observed in IL-6/PTH-rP mice $\left(\mathrm{Ca}^{2+} 2.26 \pm 0.60 \mathrm{mmol} /\right.$ liter). This difference in $\mathrm{Ca}^{2+}$ concentrations between PTH-rP and IL-6/PTH-rP mice was a common pattern found in all four experiments. PTH-rP mice were always hypercalcemic at time of killing in subsequent experiments but never reached the degree of hypercalcemia detected in IL-6/PTH-rP animals, which usually occurred earlier and in much greater magnitude.

Effects on bone histology - mature osteoclasts. Histomorphometric analysis of calvarial sections revealed that osteoclasts and eroded surfaces were significantly increased in IL-6/ PTH-rP mice when compared with the other treatment groups (Figs. 2 and 3 ).

Effects on committed marrow osteoclast precursors. The effects of cytokines in marrow osteoclast precursors were determined in the three subsequent experiments. A significant increase of more committed osteoclast precursors, assessed by formation of TRAP(+) MNCs, but not of CFU-GM was observed in all mice with PTH-rP-producing tumors, indicating a preferential effect of PTH-rP on later stages of the osteoclast lineage (Fig. 4). However, this increase in formation of TRAP (+) MNCs was significantly higher in IL-6/PTH-rP animals compared with PTH-rP mice (Fig. 4). IL-6 did not affect mature osteoclast precursors, since mice bearing IL-6-producing tumors had similar numbers of TRAP $(+)$ MNCs when compared with control animals.

Effects on CFU-GM. CFU-GM were significantly increased in all mice bearing $\mathrm{CHO} / \mathrm{IL}-6$-producing tumors, regardless of treatment with CHO/PTH-rP (Fig. 5). The number of nonadherent bone marrow cells per femur did not differ among treatment groups for individual experiments, and thus, the data are presented as the number of CFU-GM per $10^{5}$ nonadherent cells plated. Mice bearing PTH-rP-producing tumors alone had no change in CFU-GM numbers when compared with control mice. However, mice bearing both PTH-rP and IL-6-producing tumors had an increase in CFU-GM similar to that in mice bearing IL-6-producing tumors alone. This increase in CFU-GM was significantly higher when compared with mice bearing either control or PTH-rP-producing tumors (Fig. 5).

Effects on tumor growth. The effects of cytokines on tumor growth were assessed only in those experiments in which all animals were bearing two tumors. Three independent experi- 


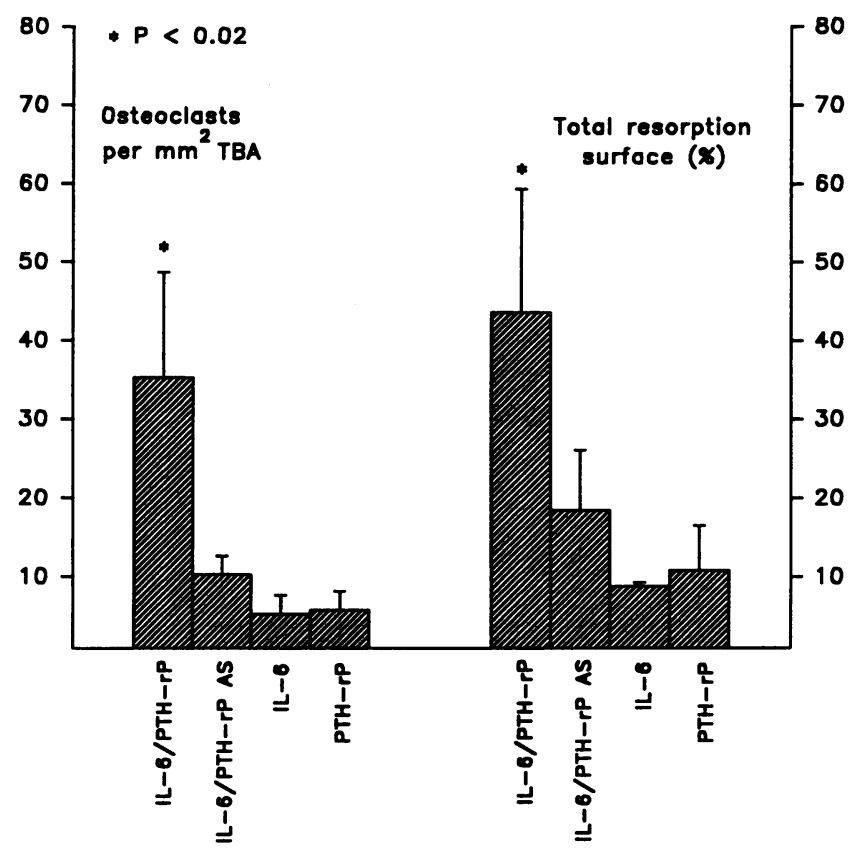

Figure 3. Effects of $\mathrm{CHO}$ tumors on calvarial bone histomorphometry. Calvariae of nude mice bearing $\mathrm{CHO} / \mathrm{IL}-6$ tumors, $\mathrm{CHO} / \mathrm{PTH}-\mathrm{rP}$ tumors, and CHO/IL-6 tumors together with $\mathrm{CHO} / \mathrm{PTH}-\mathrm{rP}$ or $\mathrm{CHO} /$ PTH-rP AS were removed $13 \mathrm{~d}$ after tumor inoculation. Osteoclast numbers are expressed per square millimeter of total bone area $(T B A)$. Resorption surfaces are expressed as a percentage of the total bone/ bone marrow interface. For each group, $n=4$. Values represent mean \pm SD. Similar effects were observed in two independent experiments.

ments showed that PTH-rP had no effect on tumor growth, as CHO/PTH-rP tumors were similar in size $\left(1.26 \pm 0.28 \mathrm{~cm}^{3}\right)$ to tumors formed in the opposite thigh by nontransfected $\mathrm{CHO}$ cells $\left(1.53 \pm 0.16 \mathrm{~cm}^{3}\right)$ and to those in control animals bearing two nontransfected CHO tumors $\left(1.68 \pm 0.11 \mathrm{~cm}^{3}\right)$ (Fig. 6). In

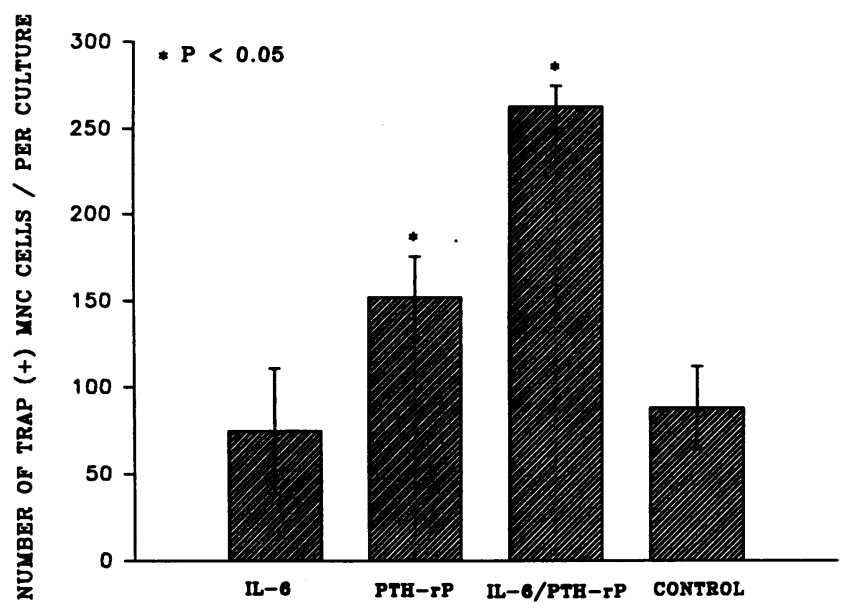

Figure 4. Effect of IL-6, PTH-rP, and the combination of both compared with controls on mature osteoclast precursors in the bone marrow. $10^{6}$ nonadherent bone marrow cells per $\mathrm{ml}$ were plated in cultures and incubated with $\alpha$-MEM plus $15 \%$ FCS and 1,25-dihydroxyvitamin $\mathrm{D}_{3}$ $\left(10^{-8} \mathrm{M}\right)$ at $37^{\circ} \mathrm{C}$ and $5 \% \mathrm{CO}_{2}$. After $6 \mathrm{~d}$, the number of $\operatorname{TRAP}(+)$ MNCs was determined. Values represent mean $\pm \mathrm{SD}$, with similar results from two independent experiments done in quadruplicate.

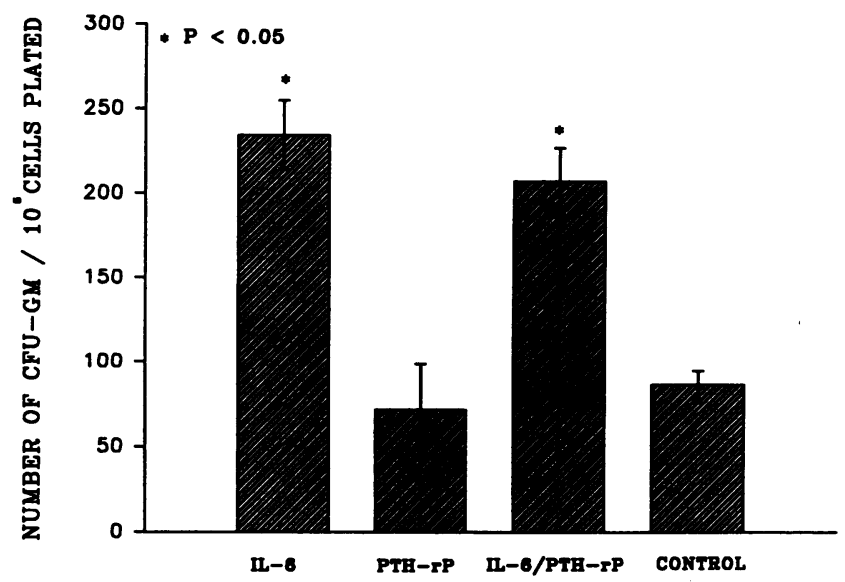

Figure 5. Effect of IL-6, PTH-rP, and the combination of both compared with controls on immature osteoclast precursors in the bone marrow. Nonadherent bone marrow cells were plated at $10^{5}$ cells per ml, with the number of CFU-GM (colonies and clusters) counted after a 7-d incubation at $37^{\circ} \mathrm{C}$ and $5 \% \mathrm{CO}_{2}$. Recombinant murine GM-CSF served as the source of colony-stimulating activity. Values represent mean $\pm \mathrm{SD}$, with similar results from three independent experiments done in triplicate.

contrast, tumors in CHO/IL-6 mice were barely palpable and were very difficult to measure, as the perimeters measured $\sim 2$ or $3 \mathrm{~mm}$. This difference in tumor volume was found in all mice bearing $\mathrm{IL}-6$-producing tumors and was observed not only in the CHO/IL-6 tumors, but also in the tumor inoculated into the opposite thigh. Thus, the volumes of $\mathrm{CHO} /-$ or $\mathrm{CHO}$ / PTH-rP tumors were markedly decreased in IL-6-treated animals (Fig. 6).

Effects of tumors on body weight. A significant loss of weight occurred by the time of killing in all mice bearing IL-6-producing tumors (Fig. 7). At this time IL-6, IL-6/ PTH-rP AS, and IL-6/PTH-rP animals presented a striking difference in body weight when compared with PTH-rP mice. PTH-rP-producing tumors had no effect on the weight of the animals, since at time of killing PTH-rP mice did not experience cachexia and IL-6/PTH-rP animals were no more cachectic than IL-6 or IL-6/PTH-rP AS mice (Fig. 7). This lack of effect of PTH-rP on weight loss and this cachectic effect of IL-6 were consistent findings in all experiments, and some IL-6 animals lost as much as $25 \%$ of their initial weight.

Cytokine assays. IL-6 and PTH-rP concentrations were undetectable in all mice before tumor inoculation (Table I). At the time of killing, PTH-rP concentrations were similar in all mice bearing $\mathrm{CHO} / \mathrm{PTH}-\mathrm{rP}$ tumors regardless of whether or not they were bearing CHO/IL-6 tumors (Table I). However, in spite of similar concentrations of PTH-rP, the degree of hypercalcemia observed in the IL-6/PTH-rP group was more marked than that in the group treated with PTH-rP alone. (Table I). At time of killing, very high concentrations of IL-6 were detected in all mice inoculated with $\mathrm{CHO} / \mathrm{IL}-6$ tumors despite the fact that the tumors were practically not palpable in these mice. However, when mice were also bearing CHO/PTH-rP or CHO/PTH-rP AS tumors, IL-6 concentrations were significantly suppressed (Table I). This decrease was more marked in IL-6/PTH-rP mice than in mice bearing CHO/IL-6 and CHO/PTH-rP AS tumors (Table I). In subsequent experiments, PTH-rP concentrations were always similar regardless of the presence of CHO/IL-6 tumors. IL-6 concentrations, in con- 


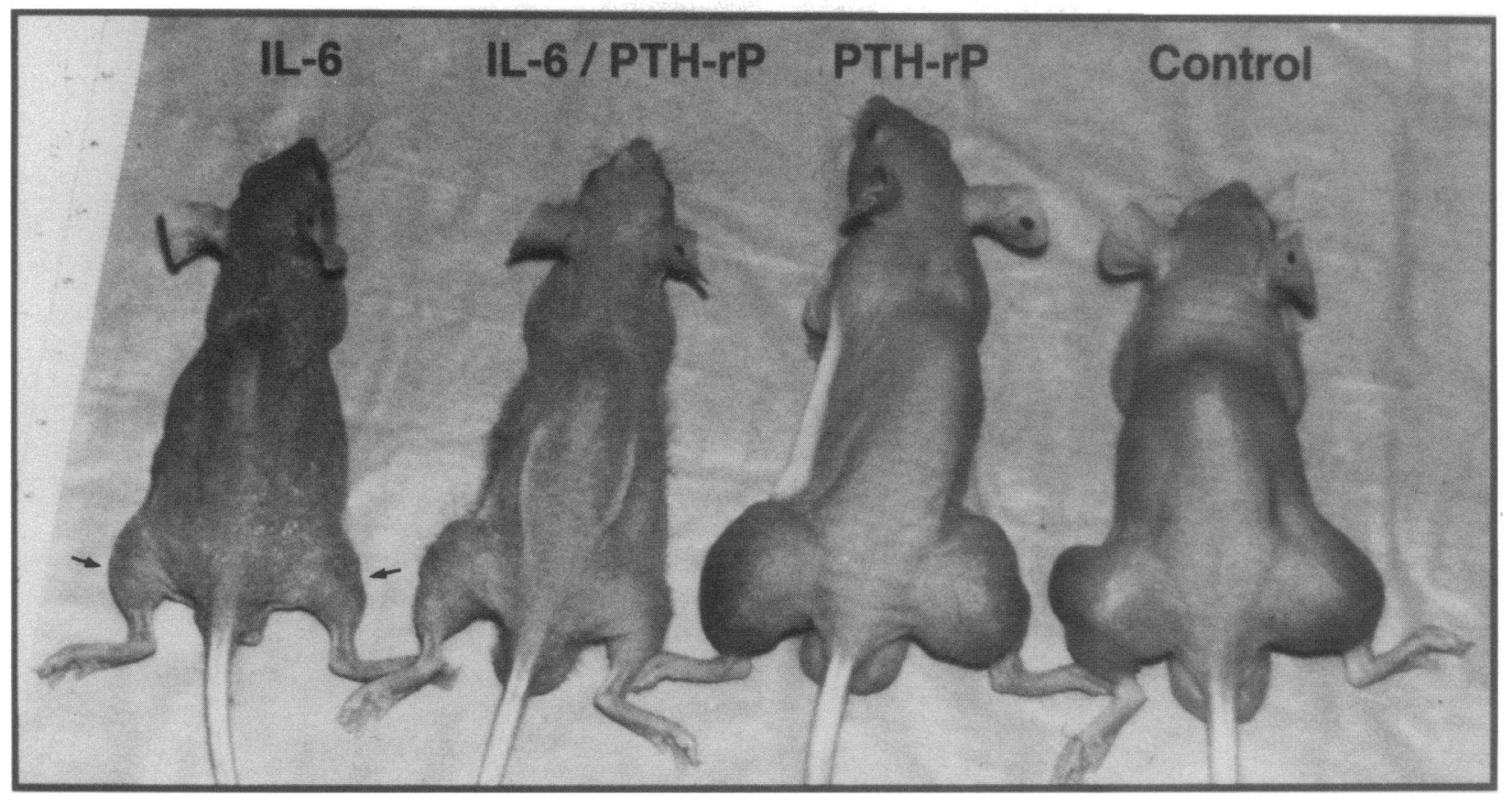

Figure 6. Effect of IL-6 on tumor growth. Mice were killed $13 \mathrm{~d}$ after the inoculation of $10^{7} \mathrm{CHO}$ cells in each thigh. CHO/IL-6 tumors were inoculated in IL-6 and IL-6/PTH-rP groups in the right thigh. Arrows indicate representative sites of inoculation of tumor cells for all mice. Mean weights at time of killing of $\mathrm{IL}-6, \mathrm{IL}-6 / \mathrm{PTH}-\mathrm{rP}$, PTH-rP, and control animals were $14.1 \pm 1.2,16.1 \pm 1.4,24.1 \pm 0.2$, and $25.1 \pm 0.5 \mathrm{~g}$, respectively. Similar effects on tumor growth were observed in three independent experiments.

trast, remained significantly decreased in the presence of $\mathrm{CHO}$ / PTH-rP tumors.

Serum samples were also tested for the presence of other cytokines. Baseline IL-1 concentrations were similar in all mice ( $\leq 111 \mathrm{pg} / \mathrm{ml}$ ). At time of killing, IL-1 concentrations tended to decrease in all groups $(\leq 68.3 \mathrm{pg} / \mathrm{ml})$ although significant differences were found only in IL-6- and PTH-rP-treated groups. TNF $\alpha$ was not detectable in any group either at baseline or at time of killing.

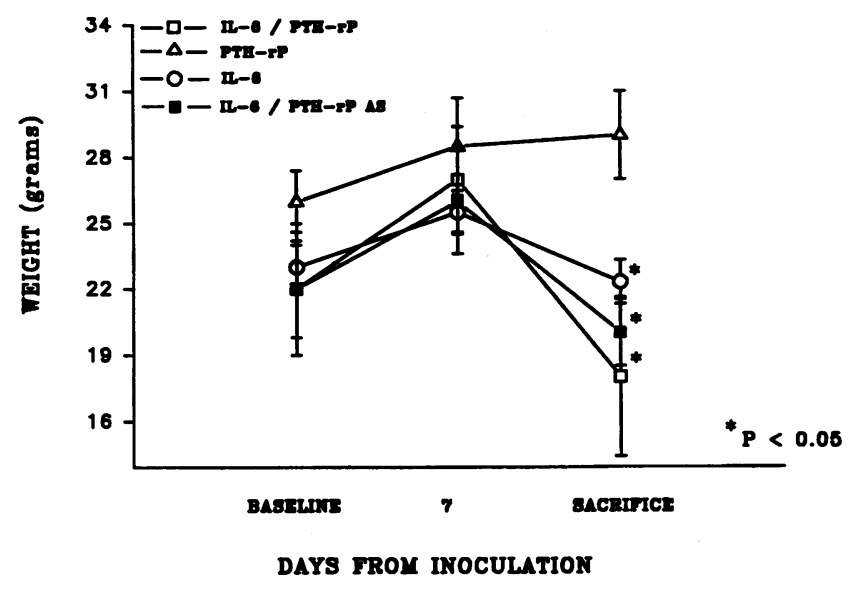

Figure 7. Effects of $\mathrm{CHO}$ tumors on body weight. Nude mice were inoculated with $\mathrm{CHO} / \mathrm{IL}-6$ tumors, $\mathrm{CHO} / \mathrm{PTH}-\mathrm{PP}$ tumors, and $\mathrm{CHO} /$ IL-6 tumors together with CHO/PTH-rP or CHO/PTH-rP AS tumors at day 0 . For each group, $n=4$. Values represent mean $\pm S D$, with similar results in four independent experiments.

\section{Discussion}

We tested the effects of tumors overexpressing IL-6 on disturbances in $\mathrm{Ca}^{2+}$ homeostasis, bone resorption, and osteoclast formation in nude mice bearing tumors expressing relatively low amounts of PTH-rP. The data presented show that IL-6 markedly potentiated the effects of PTH-rP. By examining pools of cells at various stages in the osteoclast lineage in tumorbearing mice, we found that IL-6 acted at earlier stages in the osteoclast lineage than PTH-rP. We propose that the enhancing effects of IL-6 on PTH-rP may be due to their different sites of action on osteoclast formation.

Recent studies suggest that IL-6 acts as an autocrine and paracrine bone factor that increases human osteoclast formation and bone resorption (9). IL-6 has been implicated in many pathological situations associated with bone loss, such as multiple myeloma (10), osteoporosis (11), rheumatoid arthritis (12), and Paget's disease (13). However, the paucity of information on the effects of IL-6 in vivo, as well as the controversial effects of IL-6 on bone resorption in vitro, makes the role of IL-6 in those pathological states uncertain. In this study we examined the effects of IL-6, PTH-rP, and the combination of both on $\mathrm{Ca}^{2+}$ homeostasis, bone resorption, and osteoclast formation. We found that although IL-6 is not a powerful bone resorbing factor in mice in vivo, it has prominent effects on cells in the early stages of the osteoclast lineage. PTH-rP, in contrast, is a potent hypercalcemic and bone resorbing factor that acts on cells in the later stages of the osteoclast lineage. Our data demonstrate that these different effects on osteoclast formation can be complementary when IL-6 is combined with PTH-rP. IL-6 appears to enhance PTH-rP-mediated bone resorption by increasing the pool of early osteoclast precursors that in turn can differentiate to mature osteoclasts. In vitro stud- 


\begin{tabular}{|c|c|c|c|c|c|c|}
\hline & \multicolumn{2}{|c|}{ PTH-rP pmolliter } & \multicolumn{2}{|c|}{ IL-6 $\mathrm{ng} / \mathrm{ml}$} & \multicolumn{2}{|c|}{$\mathrm{Ca}^{2+}$ mmolliter } \\
\hline & Baseline & Death & Baseline & Death & Baseline & Death \\
\hline IL-6 & $<0.3$ & $<0.3$ & $<0.015$ & $13.6 \pm 0.5^{8}$ & $1.25 \pm 0.02$ & $1.3 \pm 0.09$ \\
\hline PTH-rP & $<0.3$ & $6.41 \pm 1.1^{*}$ & $<0.015$ & $<0.05$ & $1.3 \pm 0.01$ & $1.42 \pm 0.07$ \\
\hline IL-6/PTH-rP & $<0.3$ & $8.22 \pm 1.2^{\ddagger}$ & $<0.015$ & $3.4 \pm 0.2^{11}$ & $1.27 \pm 0.01$ & $2.26 \pm 0.3^{* *}$ \\
\hline IL-6/PTH-rP AS & $<0.3$ & $<0.3$ & $<0.015$ & $6.8 \pm 2^{1}$ & $1.29 \pm 0.004$ & $1.31 \pm 0.008$ \\
\hline
\end{tabular}

Blood was obtained before tumor inoculation and at time of killing on day 13. The lowest detectable concentrations of PTH-rP and IL-6 were 0.3 $\mathrm{pmol} /$ iter and $15 \mathrm{pg} / \mathrm{ml}$, respectively, for these particular assays. For each group, $n=4$. Values represent mean $\pm \mathrm{SD}$. ${ }^{*} P<0.001$ compared with IL-6 and IL-6/PTH-rP AS, but not significantly different from IL-6/PTH-rP. ${ }^{\ddagger} P<0.001$ compared with IL-6 and IL-6/PTH-rP AS, but not significantly different from IL-6/PTH-rP. ${ }^{\$} P<0.001$ compared with PTH-rP, IL-6/PTH-rP, and IL-6/PTH-rP AS. " $P<0.001$ compared with IL-6, PTH-rP, and IL-6/PTH-rP AS. ' $P<0.001$ compared with IL-6, PTH-rP, and IL-6/PTH-rP. ${ }^{* *} P<0.05$ compared with IL-6, PTH-rP, and IL-6/PTH-rP AS.

ies have suggested that the effect of IL-6 on osteoclastogenesis may be necessary to mediate PTH-rP-stimulated bone resorption. Organ cultures from IL-6 knockout mice show significantly less bone resorption, when treated with PTH-rP, than organ cultures from $+/+$ littermates. This decreased response to PTH$\mathrm{rP}$ was overcome with addition of IL-6 to these organ cultures (14). These data are also consistent with our findings.

The hypercalcemic responses we observed in these experiments demonstrate that $\mathrm{IL}-6$ is not a hypercalcemic agent, since only a few mice with extremely high plasma IL-6 concentrations became hypercalcemic (data not shown). Mice bearing PTHrP tumors alone had a moderate increase in $\mathrm{Ca}^{2+}$ concentrations that was not significantly different from baseline values at day 13. This probably reflects the beginning of an upward trend in $\mathrm{Ca}^{2+}$ that would have reached higher concentrations if the mice were allowed to survive longer (6). The combined effect of IL-6 and PTH-rP produced an earlier and much greater hypercalcemic response than either agent alone, indicating an enhancing effect of IL-6 on PTH-rP despite the fact that IL-6 concentrations in the IL-6/PTH-rP group were significantly lower compared with IL-6 and IL-6/PTH-rP AS mice. Currently, the reasons why IL-6 concentrations are lower in IL-6/PTH-rP mice than in any other group bearing IL-6-producing tumors remain obscure, but this finding indicates that only very modest concentrations of IL-6 are necessary to enhance the effect of PTH-rP. In vitro studies have shown that PTH and PTH-rP stimulate IL-6 production from primary rat osteoblast-like cells as well as from an osteosarcoma cell line (15). In the present study, IL-6 was not detectable in the plasma of mice bearing PTH-rP-producing tumors. Thus, in this model, systemic concentrations of IL-6 do not appear to be enhanced by PTH-rP in vivo.

Several mechanisms may be involved in the potentiating effect of IL-6 on PTH-rP-mediated hypercalcemia. Possible IL-6 modulation of PTH-rP-stimulated renal tubular resorption of $\mathrm{Ca}^{2+}$ was not investigated in this study, and therefore a potential enhancing effect of $\mathrm{IL}-6$ on tubular resorption of $\mathrm{Ca}^{2+}$ cannot be ruled out. However, the complementary effect of these factors on osteoclastosis (Fig. 4) appears to be a likely mechanism by which IL-6 enhances PTH-rP-mediated hypercalcemia. The effects of IL-6 on early stages of the osteoclast lineage have been well defined in vitro (16). The data presented here confirm those previous studies and demonstrate that PTH-rP acts at later stages in the osteoclast lineage. The larger pool of earlier osteoclast progenitors in CHO/IL-6 mice pro- vides more precursors on which PTH-rP can exert its effects. This results in a net increase in more committed osteoclast progenitors, which leads to increase osteoclast formation and osteoclastic bone resorption. These IL-6 effects on immature osteoclast progenitors seem to represent an important mechanism by which IL-6 can enhance the bone resorption produced by other factors that act at later stages in osteoclast lineage. However, kinetic data demonstrating that these early precursors eventually form osteoclasts would be required to prove this hypothesis. Such experiments are currently not feasible. The production of other bone resorbing cytokines as a consequence of the tumor bearing state or the overexpression of these two factors by $\mathrm{CHO}$ tumors could contribute to the effects detected here. The facts that IL-1 concentrations decreased and TNF $\alpha$ concentrations remained undetectable throughout the experiments suggest that our findings cannot be attributed to a contribution by these two cytokines.

IL-6 has been directly involved in the development of experimental cancer cachexia (17). Previous reports have shown that mice bearing $\mathrm{CHO} / \mathrm{IL}-6$-producing tumors developed a very marked loss of weight when compared with mice bearing $\mathrm{CHO}$ tumors not expressing IL-6 (5). However, it is difficult to delineate the precise role of $\mathrm{IL}-6$ in cancer cachexia in vivo, since other cytokines with cachectic effects, such as IL-1 and TNF, may be coproduced with IL-6 in those circumstances. The changes of body weight reported here confirm previous findings, as all mice bearing IL-6-overexpressing tumors experienced a very marked loss of weight regardless of whether they were also inoculated with CHO/PTH-rP or CHO/PTH-rP AS tumors. Our data demonstrate that IL-1 and TNF $\alpha$ apparently do not contribute to the effects reported here. These results provide additional evidence that support IL-6 as a major cachectic factor and suggest that its cachectic activity seems to be independent of other cachectic cytokines, such as TNF $\alpha$ or IL-1.

CHO/IL-6 mice displayed a striking decrease in tumor growth. The exogenous administration of $\mathrm{IL}-6$ to mice bearing tumors has been reported to inhibit tumor growth in vivo, suggesting a potential inhibitory effect of $\mathrm{IL}-6$ on tumor growth (18). However, depending on the tumor cell line, IL-6 has been shown to have potent inhibitory effects (19), potent stimulatory effects (20), or no effects on tumor growth (21). In our study, the striking difference found in the volume of $\mathrm{CHO} /-$ and CHO/PTH-rP tumors in the presence or absence of IL-6 strongly suggests an anti-tumor effect of $\mathrm{IL}-6$ in this model. This anti-tumor effect exhibited by IL-6 may explain why $\mathrm{CHO}$ / 
IL-6 tumors were always very small and why second tumors in CHO/IL-6 tumor-bearing mice never reached the proportions that similar tumors reached in mice not bearing $\mathrm{CHO} / \mathrm{IL}-6$ tumors.

Taken together, these in vivo data suggest that the role of IL-6 is as an enhancer or helper factor rather than as a primary bone resorbing factor in pathological conditions associated with increased bone resorption. Accordingly, these results may also explain why osteoclastosis is greater in patients with humoral hypercalcemia of malignancy than in those with primary hyperparathyroidism, a state of PTH excess. Additional studies of this nature may lead to a better understanding of the role of IL-6 in pathological conditions associated with increased bone resorption.

\section{Acknowledgments}

The authors thank Suzanne Taylor for her expert technical assistance and Thelma Barrios for her excellent preparation of the manuscript.

This work was supported by the Research Service of the Veterans Administration, by grants K08-AR01899 (T. A. Guise), DE08569 (B. F. Boyce), and PO1-AR39529 (G. D. Roodman and G. R. Mundy) from the National Institutes of Health, and by B. A. E. 93/9155 (J. De La Mata) from Fondo de Investigaciones Sanitarias (INSALUD).

\section{References}

1. Burtis, W. J., T. G. Brady, J. J. Orloff, J. B. Ersbak, R. P. Warrell, Jr., B. R. Olson, T. Wu, M. E. Mitnick, A. E. Broadus, and A. F. Steward. 1990 Immunochemical characterization of circulating parathyroid hormone-related protein in patients with humoral hypercalcemia of cancer. $N$. Engl. J. Med. 332:1151 1153.

2. Budayr, A. A., R. A. Nissenson, R. F. Klein, K. K. Pun, O. H. Clark, D. Diep, C. D. Arnaud, and G. J. Strewler. 1989. Increased serum levels of a parathyroid hormone-like protein in malignancy-associated hypercalcemia. Ann. Intern. Med. 111:807-812.

3. Yoneda, T., M. Nakai, K. Moriyama, L. Scott, N. Ida, T. Kunitomo, and G. R. Mundy. 1993. Neutralizing antibodies to human interleukin-6 reverse hypercalcemia associated with a human squamous carcinoma. Cancer Res. 53:737740 .

4. Ishimi, Y., C. Miyaura, C. H. Jin, T. Akatsu, E. Abe, Y. Nakamura, A. Yamaguchi, S. Yoshiki, T. Matsuda, T. Hirano, et al. 1990. IL-6 is produced by osteoblasts and induces bone resorption. J. Immuno P. 145:3297-3303.

5. Black, K., I. R. Garrett, and G. R. Mundy. 1991. Chinese hamster ovarian cells transfected with the murine interleukin- 6 gene cause hypercalcemia as well as cachexia, leukocytosis and thrombocytosis in tumor-bearing nude mice. Endocrinology. 128:2657-2659.

6. Guise, T. A., J. M. Chirgwin, G. Favarato, B. F. Boyce, and G. R. Mundy. 1992. Chinese hamster ovarian cells transfected with human parathyroid hormonerelated protein cDNA cause hypercalcemia in nude mice. Lab. Invest. 67:477485.

7. Mundy, G. R., and G. D. Roodman. 1987. Osteoclast ontogeny and function. In Bone \& Mineral Research. Vol. 5. W. A. Peck, editor. Elsevier Scientific Publishers, New York. 209-281.

8. Pandian, M. R., C. H. Morgan, E. Carlton, and G. U. Segre. 1992. Modified immunoradiometric assay of parathyroid hormone-related protein: clinical application in the differential diagnosis of hypercalcemia. Clin. Chem. 38:282-288.

9. Roodman, G. D. 1992. Interleukin 6: an osteotropic factor? J. Bone Miner. Res. 7:475-478.

10. van Oers, M. H. J., H. C. T. van Zaanen, and H. M. Lokhorst. 1993. Interleukin-6, a new target for therapy in multiple myeloma? Ann. Hematol. 66:219-223.

11. Jilka, R. L., G. Hangoc, G. Girasole, G. Passeri, D. C. Williams, J. S. Abrams, B. Boyce, H. Broxmeyer, and S. C. Manolagas. 1992. Increased osteoclast development after estrogen loss: mediation by interleukin-6. Science (Wash. DC). 257:88-91.

12. Houssiau, F. A., J.-P. Devogelaer, J. van Damme, C. Nagant de Deuxchaisnes, and J. van Snick. 1988. Interleukin-6 in synovial fluid and serum of patients with rheumatoid arthritis and other inflammatory arthritides. Arthritis Rheum. 31:784-788.

13. Roodman, G. D., N. Kurihara, Y. Ohsaki, A. Kukita, D. Hosking, A Demulder, F. J. Smith, and F. R. Singer. 1992. Interleukin-6: a potential autocrine/ paracrine factor in Paget's disease of bone. J. Clin. Invest. 89:46-52.

14. Most, W., E. V. Beek, C. Ruwhof, R. V. Bezooijen, A. Ederveen, M. Kopf, S. Papapoulos, and C. Löwik. 1994. Osteoclastic resorption in interleukin6 dependent mice. J. Bone Miner. Res. 9(Suppl. 1):S132. (Abstr.)

15. Löwik, C. W. G. M., G. van der Pluijm, H. Bloys, K. Koekman, O. L. M Bijvoet, L. A. Aarden, and S. E. Papapoulos. 1989. Parathyroid hormone (PTH) and PTH-like protein (PLP) stimulate interleukin-6 production by osteogenic cells: a possible role of interleukin-6 in osteoclastogenesis. Biochem. Biophys. Res. Commun. 162:1546-1552.

16. Suda, T., Y. Yamaguchi, J. Suda, Y. Miura, A. Okano, and Y. Akiyama. 1988. Effect of interleukin-6 on the differentiation and proliferation of murine and human hematopoietic progenitors. Exp. Hematol. 16:891-895.

17. Strassman, G., M. Fong, J. S. Kenney, and C. H. O. Jacob. 1992. Evidence for the involvement of interleukin-6 in experimental cancer cachexia. J. Clin. Invest. 89:1681-1684.

18. Mule, J. J., and S. A. Rosenberg. 1990. Antitumor activity of recombinant interleukin-6 in mice. J. Exp. Med. 171:629-636.

19. Chen, L., Y. Mory, A. Zilberstein, and M. Revel. 1988. Growth inhibition of human breast carcinoma and leukemia/lymphoma cell lines by recombinant interferon- $\beta 2$. Proc. Natl. Acad. Sci. USA. 85:8037-8041.

20. Miki, S., M. Iwano, Y. Miki, M. Yamamoto, B. Tang, K. Yokokawa, T. Hirano, and T. Kishimoto. 1989. Interleukin-6 (IL-6) functions as an autocrine growth factor in renal cell carcinomas. FEBS (Fed. Eur. Biochem. Soc.) Lett. 250:607-610.

21. Serve, H., G. Steinhauser, D. Oberberg, W. A. Flegel, H. Northoff, and W. E. Berdel. 1991. Studies on the interaction between interleukin-6 and human malignant nonhematopoietic cell lines. Cancer Res. 51:3862-3866. 